\title{
Tube-Trailer Consolidation Strategy for Reducing Hydrogen Refueling Station Costs
}

\section{Amgad Elgowainy a, Krishna Reddi ${ }^{a *}$, Erika Sutherland ${ }^{b}$, and Fred Joseck ${ }^{b}$}

a Argonne National Laboratory, 9700 South Cass Avenue, Argonne, IL 60439

b U.S. Department of Energy, Fuel Cell Technologies Office, 1000 Independence Avenue SW, Washington, DC 20585

* Corresponding Author Contact: (630)-252-1479, kreddi@anl.gov

\begin{abstract}
The rollout of hydrogen fuel cell electric vehicles (FCEVs) requires the initial deployment of an adequate network of hydrogen refueling stations (HRSs). Such deployment has proven to be challenging because of the high initial capital investment, the risk associated with such an investment, and the underutilization of HRSs in early FCEV markets. Because the compression system at an HRS represents about half of the station's initial capital cost, novel concepts that would reduce the cost of compression are needed. Argonne National Laboratory with support from the U.S. Department of Energy's (DOE) Fuel Cell Technologies Office (FCTO) has evaluated the potential for delivering hydrogen in high-pressure tube-trailers as a way of reducing HRS compression and capital costs. This paper describes a consolidation strategy for a high-pressure (250-bar) tube-trailer capable of reducing the compression cost at an HRS by about $60 \%$ and the station's initial capital investment by about $40 \%$. The consolidation of tube-trailers at pressures higher than 250 bar (e.g., 500 bar) can offer even greater HRS costreduction benefits. For a typical hourly fueling-demand profile and for a given compression capacity, consolidating hydrogen within the pressure vessels of a tube-trailer can triple the station's capacity for fueling FCEVs. The high-pressure tube-trailer consolidation concept could play a major role in enabling the early, widespread deployment of HRSs because it lowers the required HRS capital investment and distributes the investment risk among the market segments of hydrogen production, delivery, and refueling.
\end{abstract}

\section{Introduction}

Hydrogen fuel cells can be used to provide power across a wide range of applications, including auxiliary, backup, and portable power systems; fuel cell electric vehicles (FCEVs); and material handling equipment. Their advantages include high efficiency and zero emissions at the point of use. These qualities, combined with the fact that the on-board hydrogen tank used to feed the fuel cell can be filled quickly, make hydrogen fuel cell technology excellent for addressing the need for zero emission vehicles while also satisfying consumer expectations for vehicle range and refueling time. In California, measures are already in place to support the adoption of these vehicles. California Assembly Bill 8, "Alternative Fuel and Vehicle Technologies: Funding Programs," was signed into law in September 2013. The bill requires the California Energy Commission (CEC) to track the number of FCEVs currently on the road and 
make projections for future years as well as to provide $\$ 20$ million per year in funding for hydrogen refueling stations [California Assembly Bill 8 2013].

There were 125 FCEVs registered with the California Department of Motor Vehicles in April 2014, and approximately 6,650 FCEVs are expected to be registered by 2017 [CARB 2014]. The availability of hydrogen refueling stations (HRSs) is the key to the adoption of FCEVs; in other words, the absence of a sufficient network of HRSs is the main barrier to the large-scale rollout of FCEVs in potential markets. Ten stations were open and operating in California as of June 2014, and 51 are expected by 2015 based on current CEC awards.

Deploying HRSs involves both a high capital investment and a high investment risk, and both are exacerbated by low utilization of these stations in early FCEV markets. To ensure the economic viability of HRS development and operation beyond that provided through CEC funding, the key cost drivers at the stations need to be addressed.

The Society of Automotive Engineers (SAE) has been developing the SAE J2601 refueling protocol, which defines safety limits and performance requirements for gaseous hydrogen refueling. The protocol covers several refueling pressures (e.g., 350 bar and 700 bar), as well as a wide range of ambient and precooling temperatures for fast fueling of fuel cell vehicles [SAE 2010]. Fast fueling of 700-bar FCEV onboard storage tanks requires a significant amount of compression throughput, refrigeration, and high-pressure storage equipment at refueling sites. The compression system represents approximately half of the initial capital cost of HRSs [Parks et al. 2014]. The fact that refueling costs are dominated by compression cost motivated our investigation of the potential for high-pressure tube-trailer delivery to reduce refueling station compression cost, thereby decreasing initial station investment costs.

\section{Background}

\subsection{Tube-Trailer Transport and Refueling of Gaseous Hydrogen}

Figure 1 shows a schematic representation of tube-trailer hydrogen delivery for vehicle refueling. One possible delivery pathway [Bolat 2014] for the hydrogen produced at a central production plant would be to transport it through a pipeline to a distribution gas terminal, where it would be compressed and loaded into pressure vessels mounted on a trailer (hereafter referred to as a tube-trailer) and trucked to fueling stations. Another possibility is that a gas terminal could be located next to the production plant, where produced hydrogen could be directly loaded into the tube-trailer. Compressed hydrogen storage is typically provided at the distribution gas terminals to address mismatches between supply and demand, satisfy demands during scheduled or unscheduled plant downtimes, and quickly fill (i.e., fast fill) tube-trailers. The filled tube-trailer is then transported from the distribution gas terminal to the fueling station, where it replaces the empty tube-trailer. At the fueling station, gaseous hydrogen from the tube-trailer pressure vessels is typically compressed further and then stored in a high-pressure buffer storage system. 
The function of high-pressure buffer storage is to satisfy a predefined dispensing rate during peak-demand hours. The hydrogen from the high-pressure buffer storage system is usually precooled before it is dispensed into the vehicle tank. The dispenser measures the flow rate of hydrogen and keeps track of the amount of hydrogen dispensed into the vehicle's onboard storage tank. Most FCEVs have Type IV onboard storage tanks, which are designed to handle 700-bar service pressure; such tanks require hydrogen to be precooled to $-40^{\circ} \mathrm{C}$ for fast refueling at a rate of approximately $1.7 \mathrm{~kg} / \mathrm{min}$.

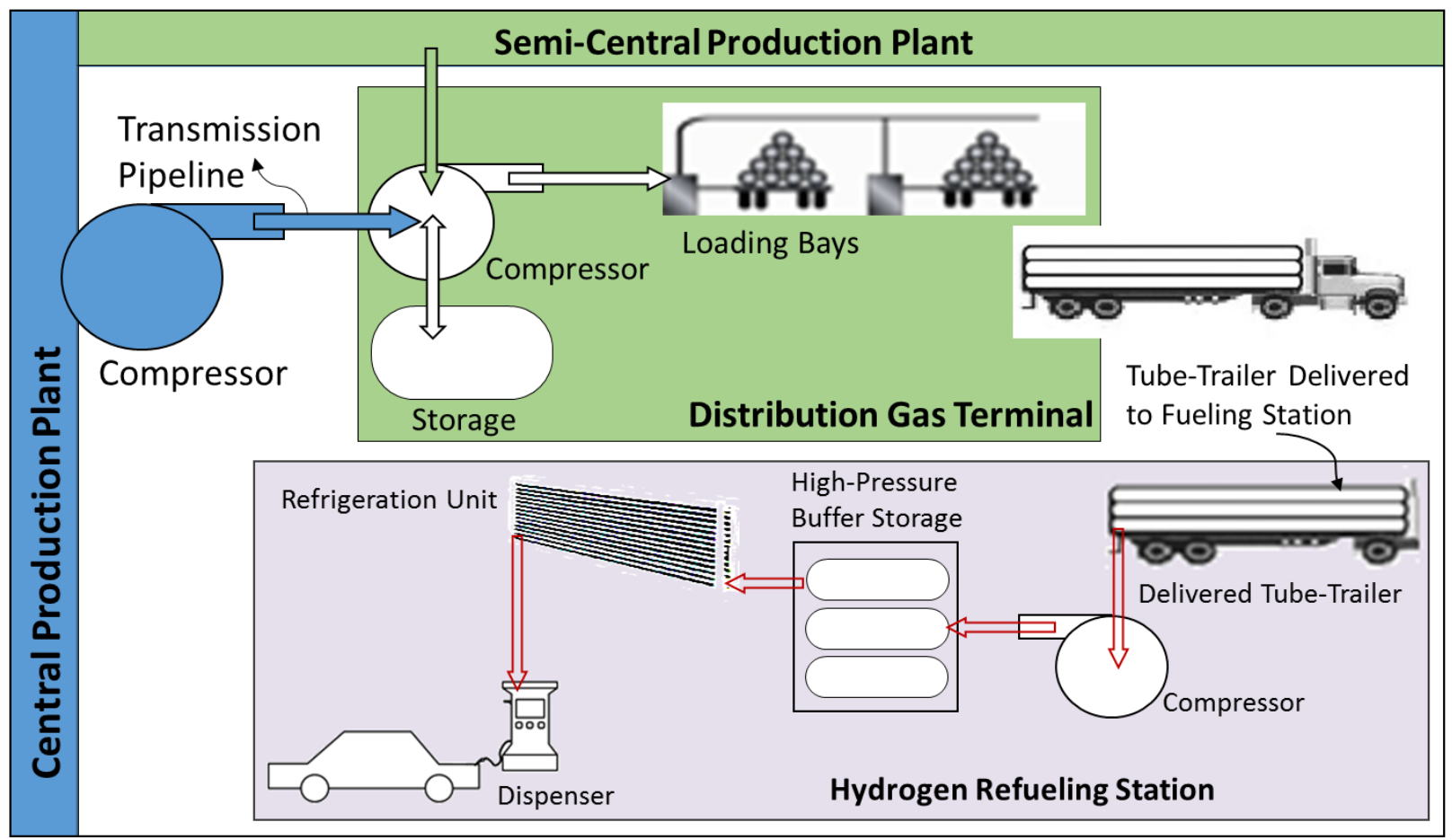

Figure 1: Schematic Representation of Hydrogen Tube-Trailer Delivery

\subsection{Cost of Hydrogen at the Dispenser}

The cost of hydrogen at the point of delivery (normally a dispenser) comprises the production cost and delivery cost. The production cost of hydrogen includes all costs incurred in producing hydrogen from its feedstock, while the delivery cost includes costs associated with transporting, distributing, and dispensing hydrogen into FCEVs. The mode by which hydrogen is delivered from the production facility to the refueling station depends on various factors, including the capacity of the receiving fueling station, the frequency of demand, and the transportation and distribution (T\&D) distance. When FCEV market penetration is high (i.e., when FCEVs in a given market have a hydrogen demand of about $50 \mathrm{MT} / \mathrm{d}$ [50 metric tons per day] or more and HRSs have capacities of about $500 \mathrm{~kg} / \mathrm{d}$ or more), the most economical delivery modes are presumed to be pipelines and liquid hydrogen trucks. When FCEV market penetration is lower (i.e., when FCEVs require HRSs capacities of 50 to $500 \mathrm{~kg} / \mathrm{d}$ ), tube-trailers might be the most economical delivery mode [Chen 2008].

In general, the HRS alone contributes about half to the total hydrogen delivery cost, mainly because of the high initial capital investment [Mintz et al. 2009]. Low utilization of the installed HRS 
equipment in early FCEV markets escalates the contribution of the HRS to that cost even more [Elgowainy et al. 2011]. The compression component alone makes up about half of the HRS installed capital cost across HRSs with various capacities [Parks et al. 2014]. Other major refueling components that affect the HRS costs are the high-pressure buffer storage system, the dispensers, and the refrigeration/heat exchanger (HX) equipment.

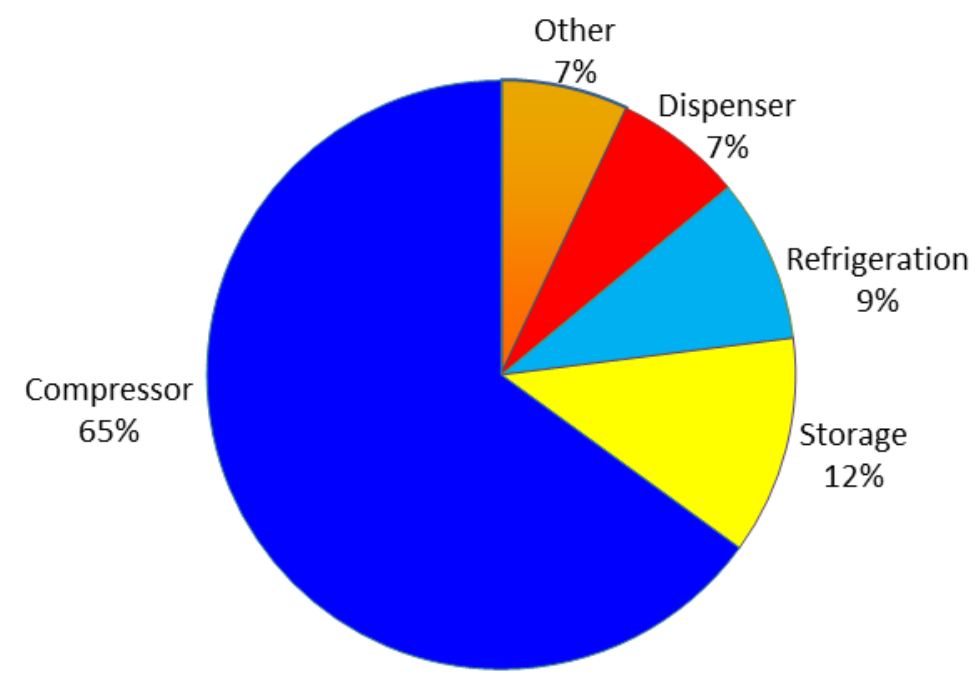

Figure 2: Cost Contribution of Each Station Component (Parks et al. 2014)

The capacities of the compressor and high-pressure buffer storage are interdependent and defined by the HRS's hourly fueling-demand profile. Higher compressor throughput requires less buffer storage, and vice versa [Elgowainy et al. 2013]. To minimize the hydrogen refueling and HRS total capital costs, it is important to optimize the required compressor throughput and the size of the high-pressure buffer storage as two interdependent components in the refueling system. The optimum capacities of these two major pieces of equipment depend on several factors: their installed cost and operational cost, the throughput of the compressor at various suction pressures, and the amount of hydrogen that needs to be dispensed during peak-demand hours. Since the compressor represents the major share of the refueling cost, this study examines the potential that high-pressure tube-trailer delivery can reduce the contribution of station compression to the refueling cost. Specifically, we propose and describe, in detail, a consolidation strategy for high-pressure tube-trailers that is capable of achieving large reductions in HRS compression costs.

We present our modeling estimates of refueling costs for three different tube-trailer management strategies at refueling stations that are optimized for minimum refueling costs. The refueling station components [Lipman 2103] included in our simulation model are (1) a compressor that draws hydrogen from a tube-trailer (delivered to the station) and discharges it to a high-pressure storage buffer, (2) a dispenser that controls the flow rate of hydrogen from the high-pressure storage buffer to the onboard vehicle storage tank, (3) a refrigeration/HX unit installed between the highpressure buffer and the dispenser to precool the hydrogen to $-40^{\circ} \mathrm{C}$, (4) FCEVs with 700 -bar onboard 
storage systems, and (5) an hourly fueling-demand profile (supplied by Chevron and based on statistics from its gasoline stations) [Chen 2008].

\section{Modeling Approach}

\subsection{Tube-Trailer Technologies}

Delivering hydrogen by using tube-trailers is considered the most economical option for early FCEV markets, when the HRS daily demand is low (up to about $500 \mathrm{~kg} / \mathrm{d}$ ) and the installed capacities are grossly underutilized [Chen 2008, Yang 2007]. Tube-trailers currently deliver hydrogen by using pressure vessels made of steel or composites that are mounted on a trailer and delivered via a truck to demand sites. Each of these materials has advantages and disadvantages. Tube-trailers made of steel are less costly to build, but the wall thickness and hence the weight of the pressure vessels increases monotonically with the service pressure. Thus, steel tube-trailers are limited in capacity by on-road weight restrictions; they can transport a hydrogen payload of up to $300 \mathrm{~kg}$ in a single trip. The maximum allowed weight in most U.S. states is $36,000 \mathrm{~kg}(80,000 \mathrm{lb})$ [U.S. Department of Transportation 1994]. Composite tube-trailers use Type III (aluminum liner wrapped with carbon fiber composite) or Type IV (plastic polyethylene liner wrapped with carbon fiber composite) pressure vessels that are lighter in weight, can withstand higher pressures (currently up to 500 bar), and thus can transport a greater hydrogen payload (up to $1,000 \mathrm{~kg}$ in a single trip). For our baseline analysis of the impact of highpressure tube-trailers on refueling station costs, we employed the configuration of the TITAN ${ }^{\mathrm{TM}} 4$ tubetrailer module manufactured and marketed by Hexagon Lincoln [2014]. The TITAN 4 module is made of four large Type IV pressure vessels, with a working pressure of 250 bar. For our simulations, we used a 250-bar, four-vessel tube-trailer fitted in an ISO-approved (ISO is the International Organization for Standardization) container with a total hydrogen payload of $640 \mathrm{~kg}$.

\subsection{High-Pressure Tube-Trailer Operation Strategies to Reduce Refueling Station Costs}

We modeled several operation strategies for the TITAN 4 high-pressure tube-trailer at the refueling station to identify and quantify possible ways to reduce station investment and operational costs. As shown in Figure 1, a hydrogen refueling station includes a hydrogen supply source (a tubetrailer in this case), compressor, high-pressure buffer storage system, refrigeration/HX unit, dispenser, and other control hardware. The high-pressure buffer storage system consists of several banks of vessels that operate within different pressure windows to cascade the hydrogen fueling into the vehicle's tank. When a vehicle pulls in for refueling and the dispenser is activated, a link is established between the vehicle tank and the cascade banks, allowing the free flow of hydrogen from the bank vessels to the vehicle tank. As the pressures in the bank vessels and vehicle tank equalize and the hydrogen flow rate reaches a predefined switching flow rate, the dispenser switches to the next bank of vessels with a higher pressure (than the vehicle's tank pressure) to complete filling the vehicle tank. Meanwhile, the compressor can operate to replenish the idle banks of vessels (i.e., those not discharging to the dispenser) in a predefined order. When all the pressure vessels in the tube-trailer are drawn down to the return pressure, the tube-trailer is replaced with another fully loaded tube-trailer. 
The number of vehicles that can be filled with a specific set of refueling station components is constrained by the refueling station's capacity and the hourly fueling-demand profile. The hourly fueling-demand profile used for simulating the operation of the refueling station was provided by Chevron [Chen 2008] and based on data from more than 400 of their gasoline refueling stations (Figure 3). The operation of the modeled refueling station, including the component specifications and process parameters, is discussed next.

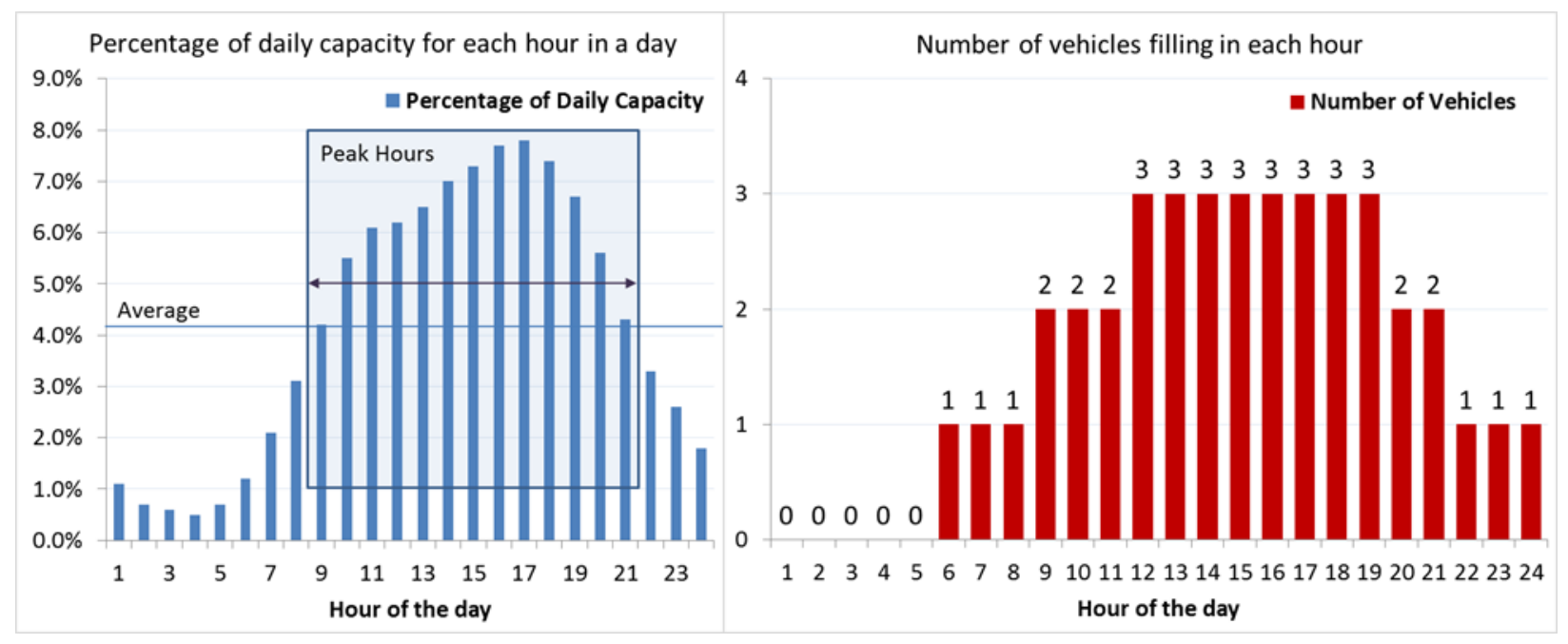

Figure 3: Hourly Fueling-Demand Profile (left) and Number of Vehicles for Each Hour for 200-kg/d Station Daily Capacity (right)

\subsubsection{Model Definition}

A comprehensive hydrogen station cost optimization and performance evaluation (H2SCOPE) [Reddi et al. 2014] model was developed to simulate the operation of HRSs. The H2SCOPE model optimizes the station components for any specific capacity and hourly fueling-demand profile. The model evaluates the performance of alternative station operating strategies to identify the configuration that results in the lowest hydrogen refueling cost.

The H2SCOPE model solves the physical laws of mass, momentum, and energy conservation as well as the hydrogen equation of state and other thermodynamic property relationships subject to specified initial and boundary conditions. It tracks mass, pressure, and temperature over time at various points of interest, such as the dispenser and high-pressure buffer storage locations, along the path that starts at the hydrogen source (i.e., the tube trailer) and goes to the vehicle's tank.

The H2SCOPE model was developed based on the following constraints and assumptions [Reddi et al. 2014]:

1. The dispenser's outlet pressure is assumed to equal the pressure inside the vehicle tank, but the model accounts for the effect that the kinetic energy of hydrogen entering the tank has on the buildup of energy in the vehicle's tank. 
2. The heat transfer from the onboard vehicle tank is transient, with a heat transfer coefficient of $325 \mathrm{~W} / \mathrm{m}^{2}-\mathrm{K}$ at the inside wall (in contact with $\mathrm{H}_{2}$ ) and $10 \mathrm{~W} / \mathrm{m}^{2}-\mathrm{K}$ and at the outside wall (in contact with ambient air).

3. The refrigeration unit is installed between the cascade banks and the dispenser; it cools the hydrogen to $-40^{\circ} \mathrm{C}(233 \mathrm{~K})$ immediately, before it reaches the dispenser. The steady-state heat gain between the dispenser and vehicle tank is assumed to be small and is neglected.

4. The compressor always replenishes the cascade banks in order of decreasing operating pressure, starting with the highest-pressure vessel bank (i.e., it starts with the high-pressure bank and ends with the low-pressure bank).

5. Any of the buffer storage banks can either be filled or emptied at any given time, but not both (i.e., both operations cannot be carried out on the same bank simultaneously).

6. The daily demand of the refueling station is addressed by a single dispenser with one hose (appropriate for small station capacities and low demand in early markets).

7. To account for the extreme demand condition, all vehicles fueling during any hour are assumed to be filled back-to-back.

8. A "lingering time" of 3 minutes is assumed between the vehicle fills.

9. The hydrogen refueling process follows the SAE J2601 fueling protocol [SAE 2010] for 700-bar compressed-hydrogen vehicles, which includes the following core constraints:

* The maximum gas temperature in the vehicle tank should not exceed $85^{\circ} \mathrm{C}$.

* The maximum fueling pressure in the vehicle tank should not exceed 875 bar at $85^{\circ} \mathrm{C}$.

* The maximum fueling rate (equivalent to $3.6 \mathrm{~kg} / \mathrm{min}$ ) should be limited to $60 \mathrm{~g} / \mathrm{s}$.

* The target fueling time for a passenger car with a capacity of $5 \mathrm{~kg}$ of hydrogen is $\leq 3$ minutes.

* The maximum vehicle tank state of charge (full tank) is defined as $40.2 \mathrm{gH}_{2} /$ Lvehicle_tank $\left(700\right.$ bar at $15^{\circ} \mathrm{C}, 875$ bar at $\left.85^{\circ} \mathrm{C}\right)$.

\subsubsection{Refueling Station Component and Operation}

The following specifications have been used for modeling the vehicle tank, high-pressure buffer storage vessels, tube-trailer pressure vessels, and compressor:

- The 129-L, Type IV, 5-kg capacity, onboard vehicle tank has a maximum working pressure of 875 bar at $85^{\circ} \mathrm{C}$ or 700 bar at $15^{\circ} \mathrm{C}$ and a minimum pressure of 20 bar at $15^{\circ} \mathrm{C}$.

- The high-pressure buffer storage system has multiple Type IV vessels, each with a capacity of $12 \mathrm{~kg}$ and a volume of $255 \mathrm{~L}$, and the service pressure is 950 bar at $25^{\circ} \mathrm{C}$.

- The tube-trailer module consists of four Type IV pressure vessels, each with a maximum working pressure of 250 bar at $25^{\circ} \mathrm{C}$ and a minimum pressure of 20 bar at $25^{\circ} \mathrm{C}$. Each of the four pressure vessels has a capacity of about $160 \mathrm{~kg}$ stored in a volume of 8,500 L, totaling about $640 \mathrm{~kg}$.

- The PDC-13-7500/15000 compressor has an outlet temperature of $300 \mathrm{~K}$ and 950-bar outlet pressure and a suction pressure range of 20 to 260 bar. The flow rate of the compressor varies from $90 \mathrm{Nm}^{3} / \mathrm{h}$ at 20-bar suction pressure to $950 \mathrm{Nm}^{3} / \mathrm{h}$ at 250-bar suction pressure. 


\subsubsection{Tube-Trailer Operation Strategy: Scenario 1}

In this HRS operation scenario, the tube-trailer supplies hydrogen to the compressor, which replenishes the buffer storage banks to make up for the hydrogen dispensed into the vehicle tanks (refer to Figure 4). Control Unit B, next to the high-pressure buffer storage system, establishes a connection between the buffer storage banks and the compressor output or the dispenser, while Control Unit A, next to the tube-trailer, establishes a connection between the pressure vessels on the trailer and the compressor input. The refrigeration/HX unit cools the hydrogen flowing from the high-pressure buffer storage system to the dispenser. The dispenser controls the flow rate, by restricting it to a maximum rate of $3.6 \mathrm{~kg} / \mathrm{min}$ and switching the source vessel banks at the appropriate time (i.e., when the flow rate is less than the minimum allowed flow rate defined by the switching point).

\section{Scenario 1}
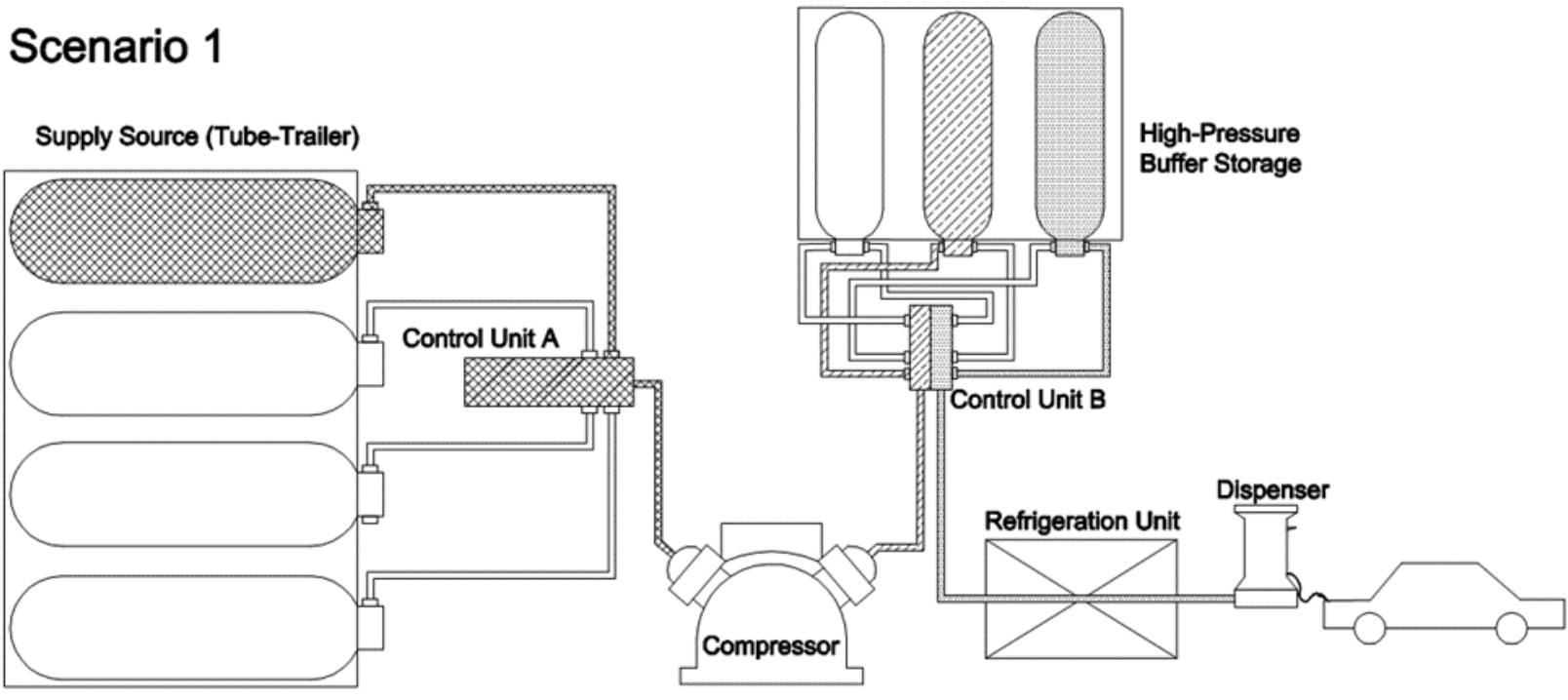

Figure 4: Schematic of Component Layout for Refueling Station Operation Scenario 1

\subsubsection{Tube Trailer Operation Strategy: Scenario 2}

In this scenario, in addition to the normal operations described for Scenario 1, the tube-trailer is used to fill the vehicle's tank during the initial dispensing period. To fill the vehicle's tank, the dispenser initially withdraws hydrogen from the vessel with the highest pressure on the tube-trailer. The highpressure buffer storage banks subsequently complete filling the vehicle, as described in Scenario 1 . This strategy employs the high pressure in the tube-trailer for the initial filling of the vehicle, thus relieving part of the burden imposed on the refueling station components (compressor and buffer storage system) in Scenario 1. While the vessel (with the highest pressure) on the tube-trailer is filling the vehicle tank, the compressor can replenish the idle buffer storage banks by drawing hydrogen from a different tube-trailer vessel, as shown in Figure 5. 


\section{Scenario 2}

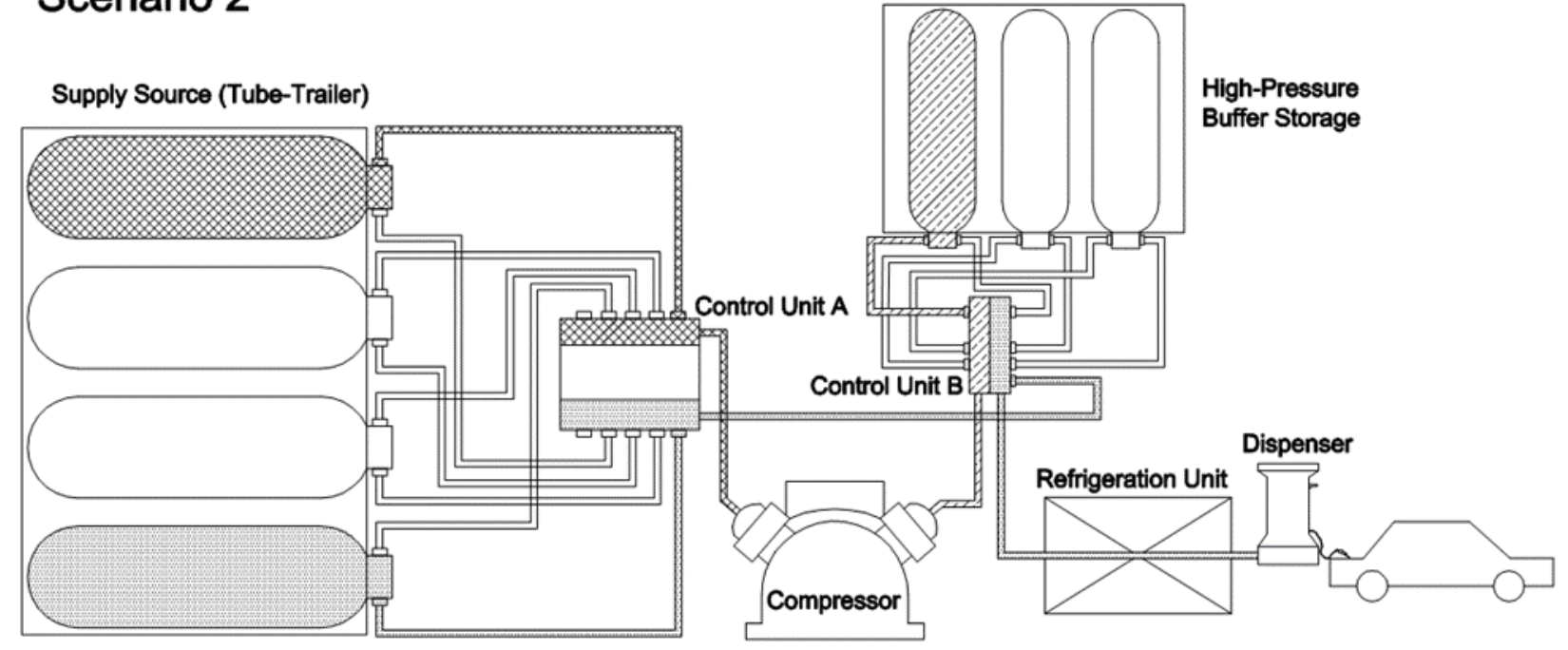

Figure 5: Schematic of Refueling Station Component Layout for Operation Scenario 2

\subsubsection{Tube Trailer Operation Strategy: Scenario 3}

In this scenario, the tube-trailer operation strategy is designed to minimize the required compression capacity at the refueling station. For a volume displacement compressor, the discharged mass flow per compression stroke is strongly correlated to the density (or the pressure) of the gas at the suction of the compressor. This is depicted in Figure 6 by the nearly linear increase in the hydrogen's flow rate with the suction pressure for the compressor we employed in this analysis. In Scenarios 1 and 2 , the compressor can compress hydrogen at a fast rate (about $950 \mathrm{Nm}^{3} / \mathrm{h}$ ) when the tube-trailer vessels are fully loaded (see flow rate in Figure 6 at 250-bar suction pressure). However, as hydrogen is drawn from the tube-trailer vessels, the pressure of the tube trailer vessels (at the compressor suction) drops, limiting the compressor's flow rate capacity. When the vessels of the tube-trailer are drawn down close to the return pressure, the compressor's ability to replenish the buffer storage banks becomes severely restricted to low flow rates (see flow rate in Figure 6 at 20-bar suction pressure). Thus, in order to accomplish back-to-back fills during peak-demand hours (Period A in Figure 7) at the targeted vehicle refueling rate ( $5 \mathrm{~kg}$ in $3 \mathrm{~min}$ ), the compressor in Scenarios 1 and 2 must be sized to provide the required throughput at the lowest allowed suction pressure, which is the return pressure of the tube-trailer.

The operation strategy in Scenario 3 aims to maintain high compressor suction pressure during peak-demand hours to amplify the compressor throughput so that it can replenish the buffer storage banks at a fast rate, thus reducing the size of the compressor and the associated high capital investment. To achieve a high compressor suction pressure during peak hours, hydrogen is consolidated within the individual pressure vessels mounted on the tube-trailer. In this context, consolidation is the process of moving the hydrogen from one tube-trailer vessel into another vessel to prepare a highpressure tube-trailer vessel for the next peak-demand period. The consolidation mainly takes place during off-peak-demand periods (see Figure 3 for peak and off-peak hours used in this simulation). 


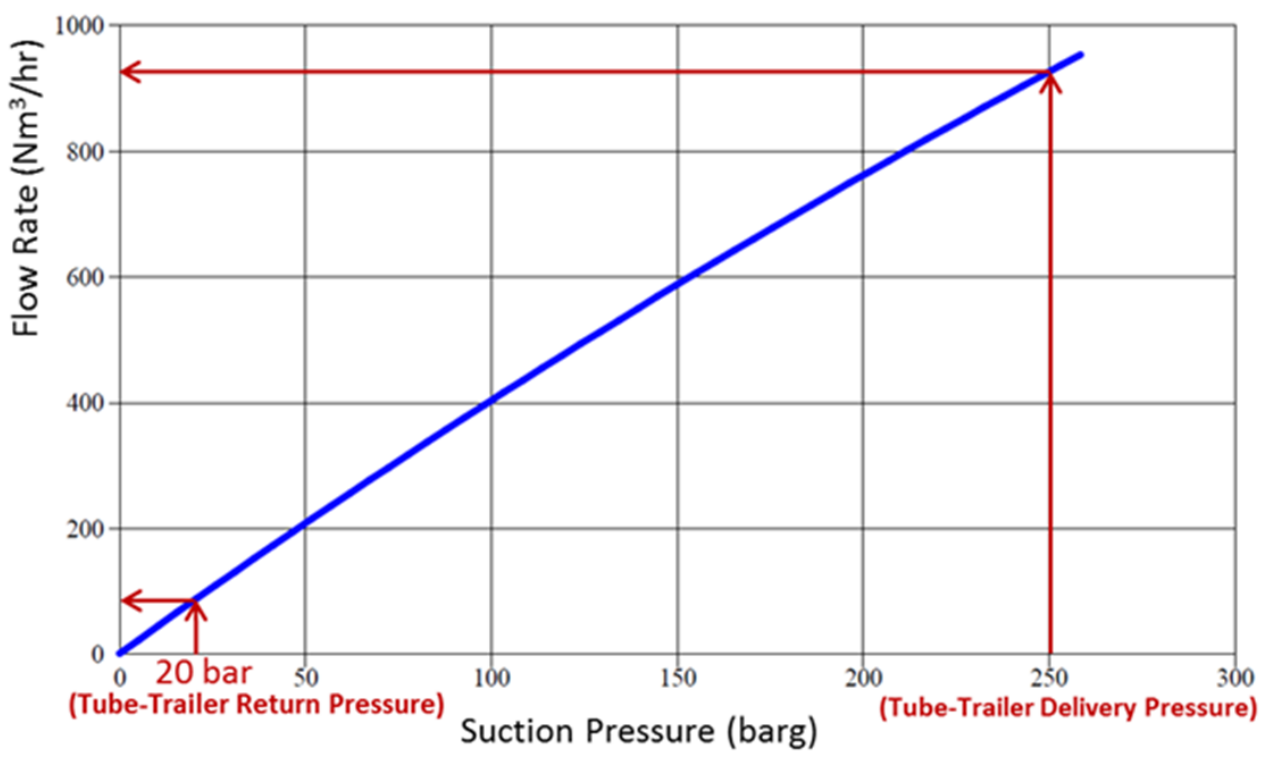

Figure 6: Flow Curve of PDC 2500/7500 Compressor

Ideally, hydrogen is consolidated within the tube-trailer, when the compressor and pressure vessels on the tube-trailer are idle. However, to simplify the simulations, we made the following assumptions:

- Only one compressor is needed at the refueling station to satisfy both the buffer storage replenishment and the tube-trailer hydrogen consolidation.

- Hydrogen is consolidated only when all buffer storage banks are at their rated working pressure and the dispenser is idle (i.e., vehicle is not being filled).

- In any given hour, hydrogen is consolidated only after all the vehicles expected for the hour are filled back to back (Period B in Figure 7).

As stated previously, all the vehicles expected within an hour are assumed to be filled back to back. Figure 7 demonstrates Period A and Period B for any hour with $n$ number of vehicles expected to be filled within the hour. Period $A$ represents the minimum time required to fill all the vehicles back to back within the hour, while Period $B$ represents the time remaining in that hour. In Period A, the operation control strategy is similar to that in Scenario 2 (see Figure 5), although the hardware configuration and connections are different. Figure 8 shows the consolidation operation, where hydrogen is consolidated in the pressure vessels on the tube-trailer during periods when there is low or no refueling demand (e.g., Period B). The three tube-trailer operation strategies (Scenarios 1-3) are summarized in Table 1. 


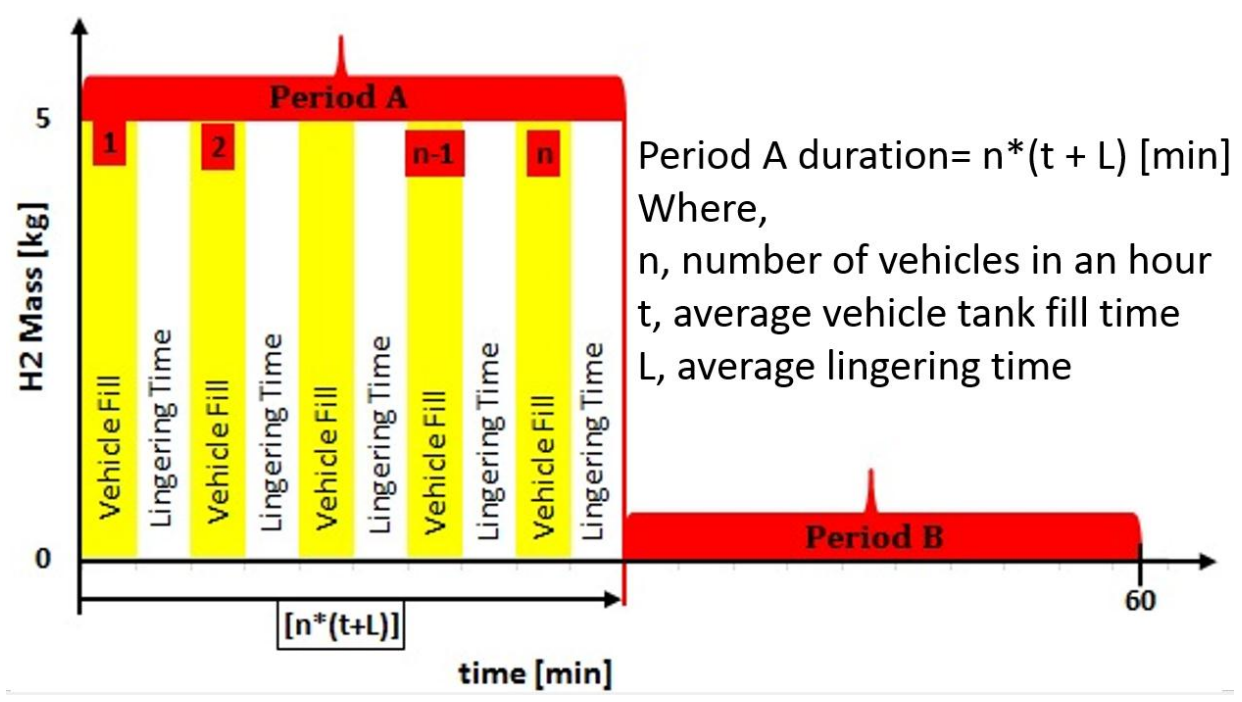

Figure 7: Fueling Profile during Period A and Period B within Each Hour

\section{Scenario 3 (Period B)}

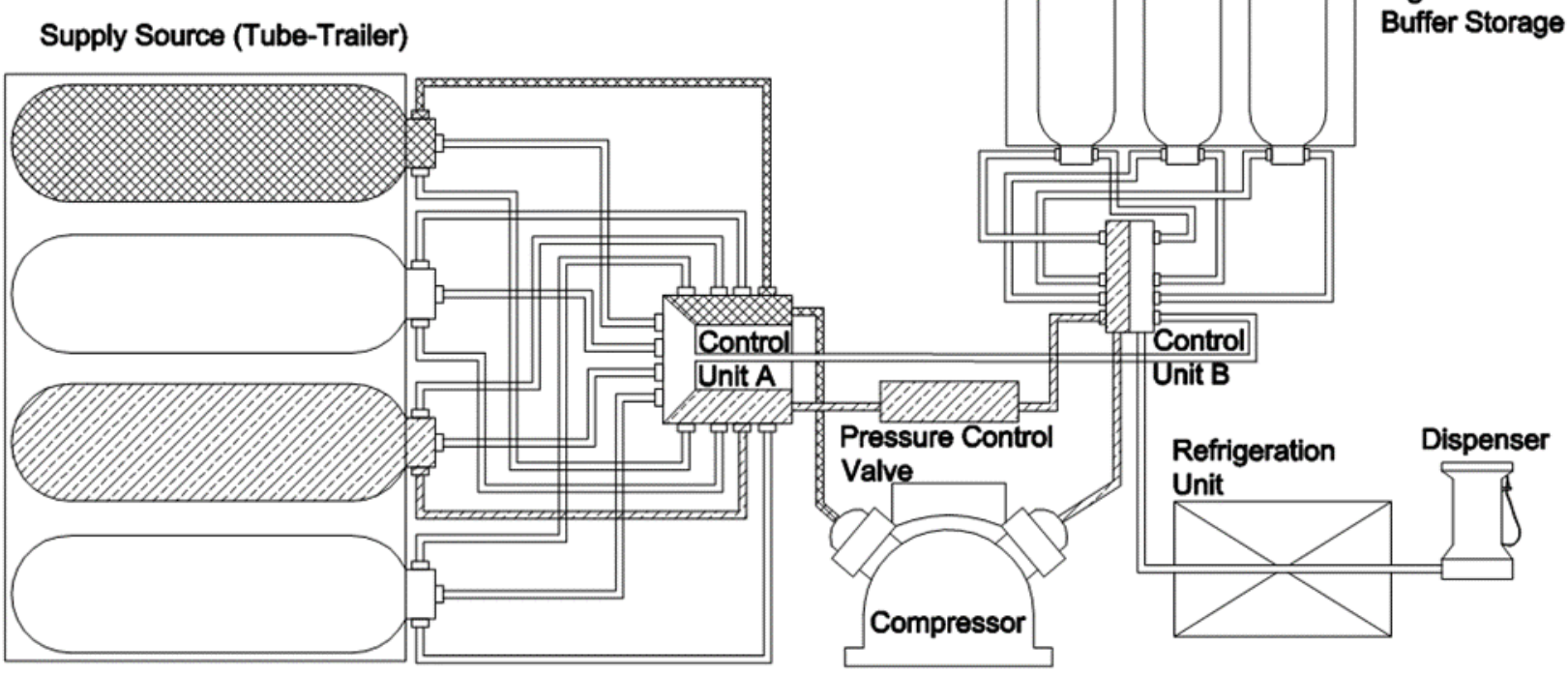

Figure 8: Schematic of Station Component Layout and Operation for Scenario 3, Period B 
Table 1: Summary of the Three Tube-Trailer Operation Scenarios

\begin{tabular}{|c|c|c|c|}
\hline \multirow[b]{2}{*}{ Operation Strategy Parameter } & \multicolumn{3}{|c|}{ Operation Strategy } \\
\hline & Scenario 1 & Scenario 2 & $\begin{array}{c}\text { Scenario } 3 \\
\text { (Periods A and B) }\end{array}$ \\
\hline Tube-trailer used for initial vehicle fill & No & Yes & Yes \\
\hline Tube-trailer hydrogen consolidation & No & No & Yes \\
\hline $\begin{array}{l}\text { Pressure of selected vessel on tube-trailer to fill } \\
\text { vehicle tank }\end{array}$ & $N A^{a}$ & Max & Max \\
\hline $\begin{array}{l}\text { Pressure of selected vessel on tube-trailer to fill } \\
\text { cascade banks }\end{array}$ & Min & Min & $\begin{array}{l}\text { Max (Period A) } \\
\text { Min (Period B) }\end{array}$ \\
\hline $\begin{array}{l}\text { Pressure of selected vessel on tube-trailer for } \mathrm{H}_{2} \\
\text { consolidation }\end{array}$ & $N A^{a}$ & $N A^{a}$ & Min \\
\hline Number of tubes in tube-trailer & 4 & 4 & 4 \\
\hline Tube-trailer capacity $\left(\mathrm{H}_{2}\right.$ in $\left.\mathrm{kg}\right)$ & 640 & 640 & 640 \\
\hline Tube-trailer capacity (no. of vehicles) & 123 & 123 & 123 \\
\hline
\end{tabular}

\section{$4 \quad$ Results and Discussion}

The H2SCOPE model was used to track the pressure, temperature, and mass transfer within and between refueling components to estimate the number of vehicles that can be filled to a $100 \%$ state of charge by following the hourly fueling-demand profile shown in Figure 3. Simulations were performed for station capacities of 100, 150, 200, 250, 300, 350, 400, and $450 \mathrm{~kg} / \mathrm{d}$. Implementation of the consolidation concept is shown in Figure 9, which illustrates the mass in each pressure vessel on the tube-trailer after every vehicle fill. The horizontal axis represents vehicles filled during the operation of the refueling station; the vertical axis represents the mass of hydrogen within each of the four vessels mounted on the trailer. An increase in hydrogen mass in a vessel indicates consolidation, while a decrease in hydrogen mass in a vessel indicates drawdown by the compressor to fill the buffer storage bank or to consolidate hydrogen by moving it to another vessel on the trailer. Figure 9 shows that as Tube 1 is emptied until it reaches the return pressure, hydrogen is consolidated in Tubes 2, 3, and 4 . After 67 vehicles are filled and Tube 1 is at return pressure, Tube 2 is used to consolidate Tubes 3 and 4 , and so on, until the three tubes (Tubes 1-3) are drawn down to the return pressure and Tube 4 ceases to satisfy the hourly fueling demand. In this case, Tube 4 use halts at a pressure higher than the return pressure of the other three tubes, with about $70 \mathrm{~kg}$ of hydrogen carried back to the terminal.

Figure 10 shows the number of vehicles that can be filled for different station capacities. The number of vehicles represents the number of complete fills that can be achieved with the assumed hourly demand profile shown in Figure 3 for a specific station capacity using the different operation strategies (Scenarios 1, 2 and 3). For example, the scenario 2 can fill 121 vehicles, i.e., about 4 days of station operation ( 30 vehicles a day delivering, $5 \mathrm{~kg}$ per fill) satisfying the hourly demand profile of a 150 $\mathrm{kg} /$ day station. This also means that the station could not dispense $5 \mathrm{~kg}$ during the $122^{\text {nd }}$ fill. The absence of a bar on the chart indicates that the station could not satisfy the minimum number of vehicles that need to be fueled with acceptable tube-trailer payload utilization. When the same 
refueling station equipment is used, the refueling station operation in Scenario 1 can satisfy a station capacity of up to $150 \mathrm{~kg} / \mathrm{d}$, while the refueling station operation in Scenario 2 can satisfy up to $200 \mathrm{~kg} / \mathrm{d}$, both with tube-trailer payload utilization above $85 \%$. However, the refueling station operation in Scenario 3 (employing the tube-trailer consolidation strategy) can satisfy a station capacity of up to 450 $\mathrm{kg} / \mathrm{d}$ with a similar payload utilization. Although Scenario 2 uses the tube-trailer to initially fill the vehicle's tank, its impact on increasing the station capacity is marginal compared with that in Scenario 1 (200 kg/d for Scenario 2 versus $150 \mathrm{~kg} / \mathrm{d}$ for Scenario 1). In Scenario 3, consolidating hydrogen between the pressure vessels on the tube-trailer triples the station capacity relative to that in Scenario 1, while achieving high utilization of the tube-trailer hydrogen payload.

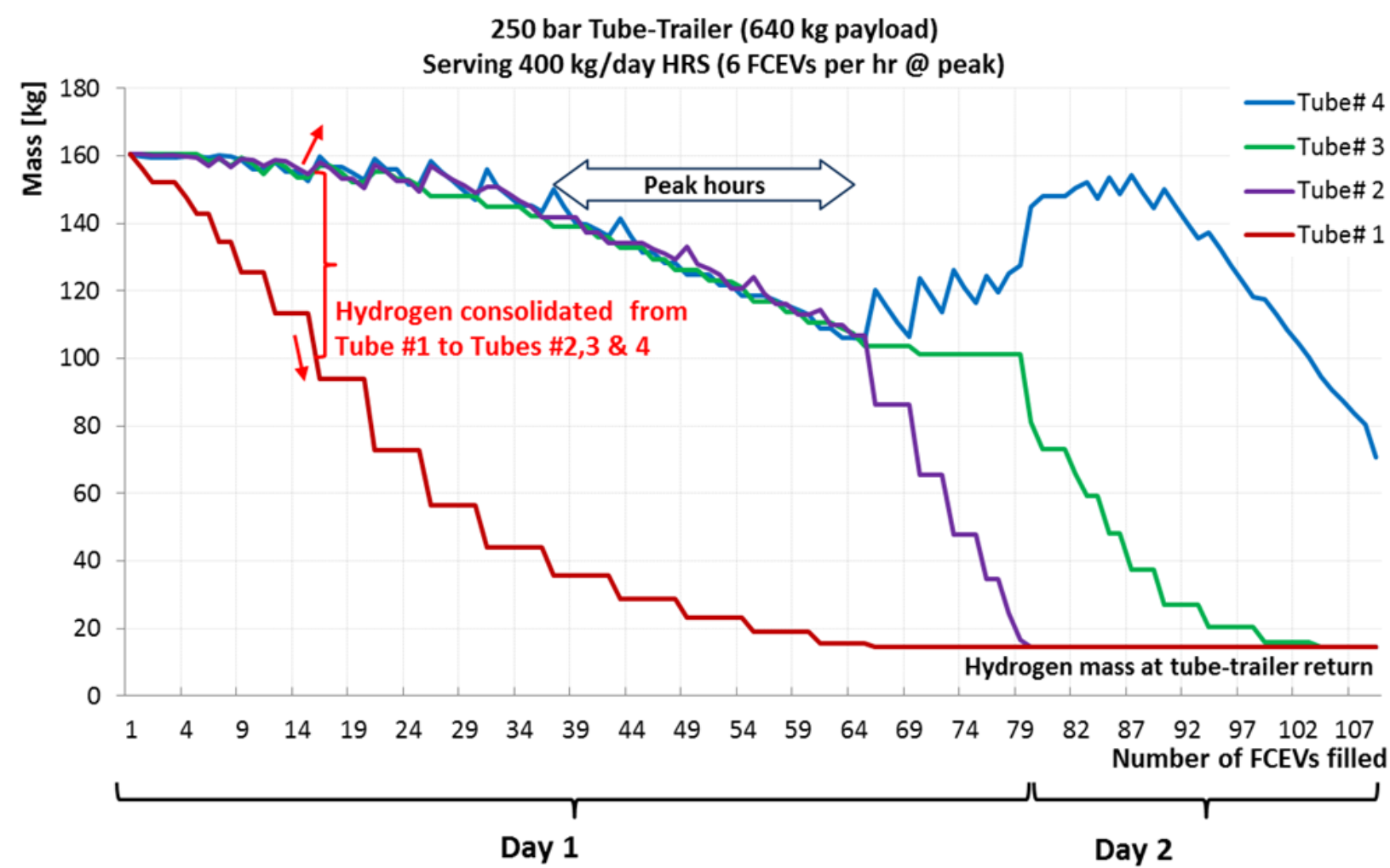

Figure 9: Status of Hydrogen Mass in Each of the Four Tube-Trailer Vessels during Operation of the Refueling Station from Using the Consolidation Strategy (Scenario 3)

Our simulations show that for the Scenario 1 operation strategy to serve the $450-\mathrm{kg} / \mathrm{d}$ station (already satisfied by Scenario 3), the compressor capacity at the return pressure (20 bar) would have to increase from 90 to $400 \mathrm{Nm}^{3} / \mathrm{h}$. Quotes from compressor manufacturers show corresponding compressor cost increases from $\$ 300,000$ for the $90-\mathrm{Nm}^{3} / \mathrm{h}$ compressor to $\$ 750,000$ for the $400-\mathrm{Nm}^{3} / \mathrm{h}$ compressor, implying a compression cost savings of $\$ 450,000$ if the consolidation strategy of Scenario 3 were employed for a station capacity of $450 \mathrm{~kg} / \mathrm{d}$. According to Figure 11, the HRS capital cost drops from $\$ 1.1$ million to $\$ 650,000$ for $450-\mathrm{kg} / \mathrm{d}$ capacity. Thus, reducing the compressor cost by $60 \%$ represents a reduction of about $40 \%$ in the total investment cost of the refueling station. Such a large cost reduction could be crucial to the economic viability of refueling stations for deployment in early FCEV markets. 


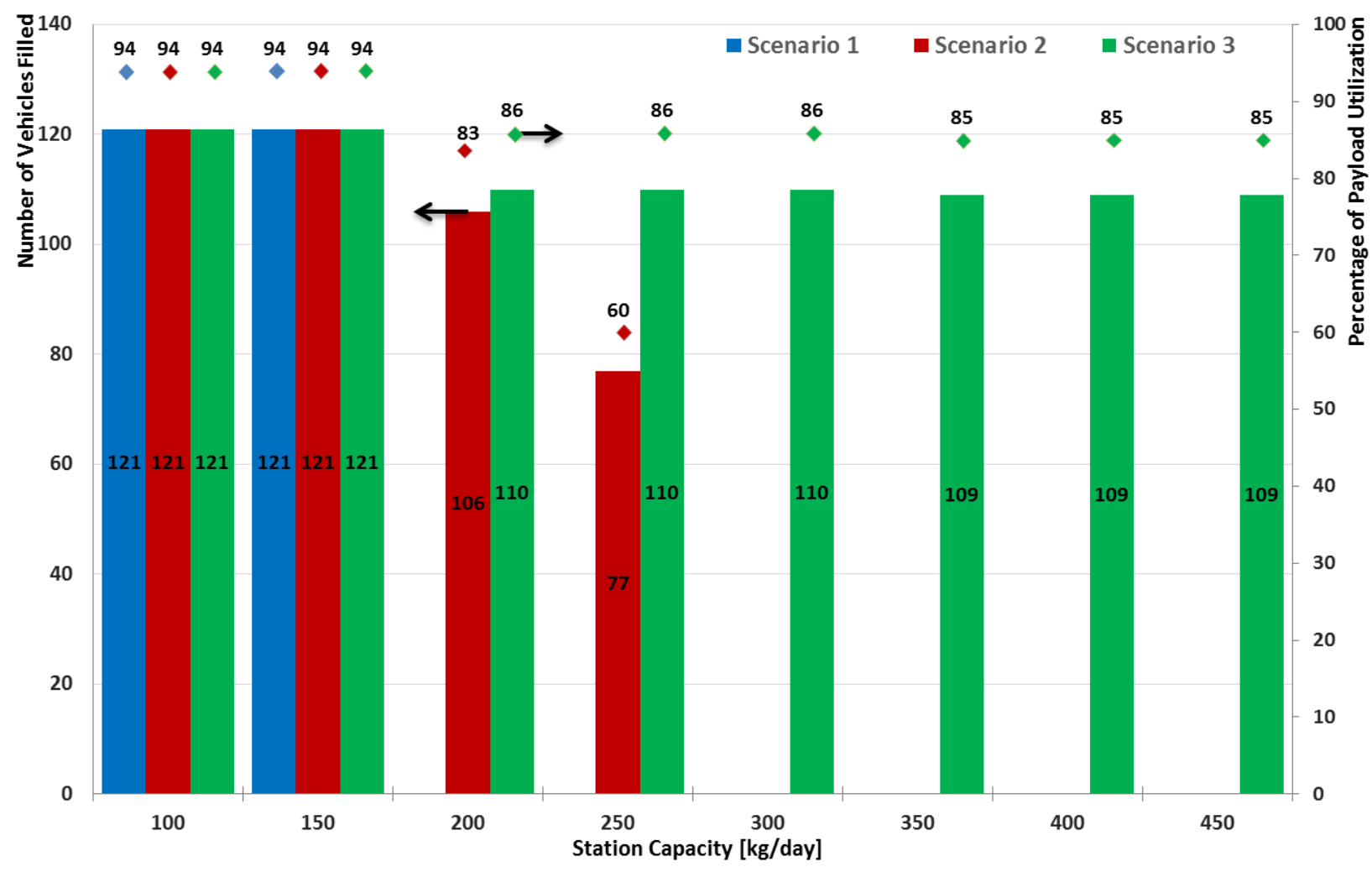

Figure 10: Total Number of Vehicles That Can Be Filled to $100 \%$ Capacity (5 kg) at a Rate of $1.7 \mathrm{~kg}_{\mathrm{H} 2} / \mathrm{min}$ and Tube-Trailer Payload Utilization for Three Tube-Trailer Operation Scenarios

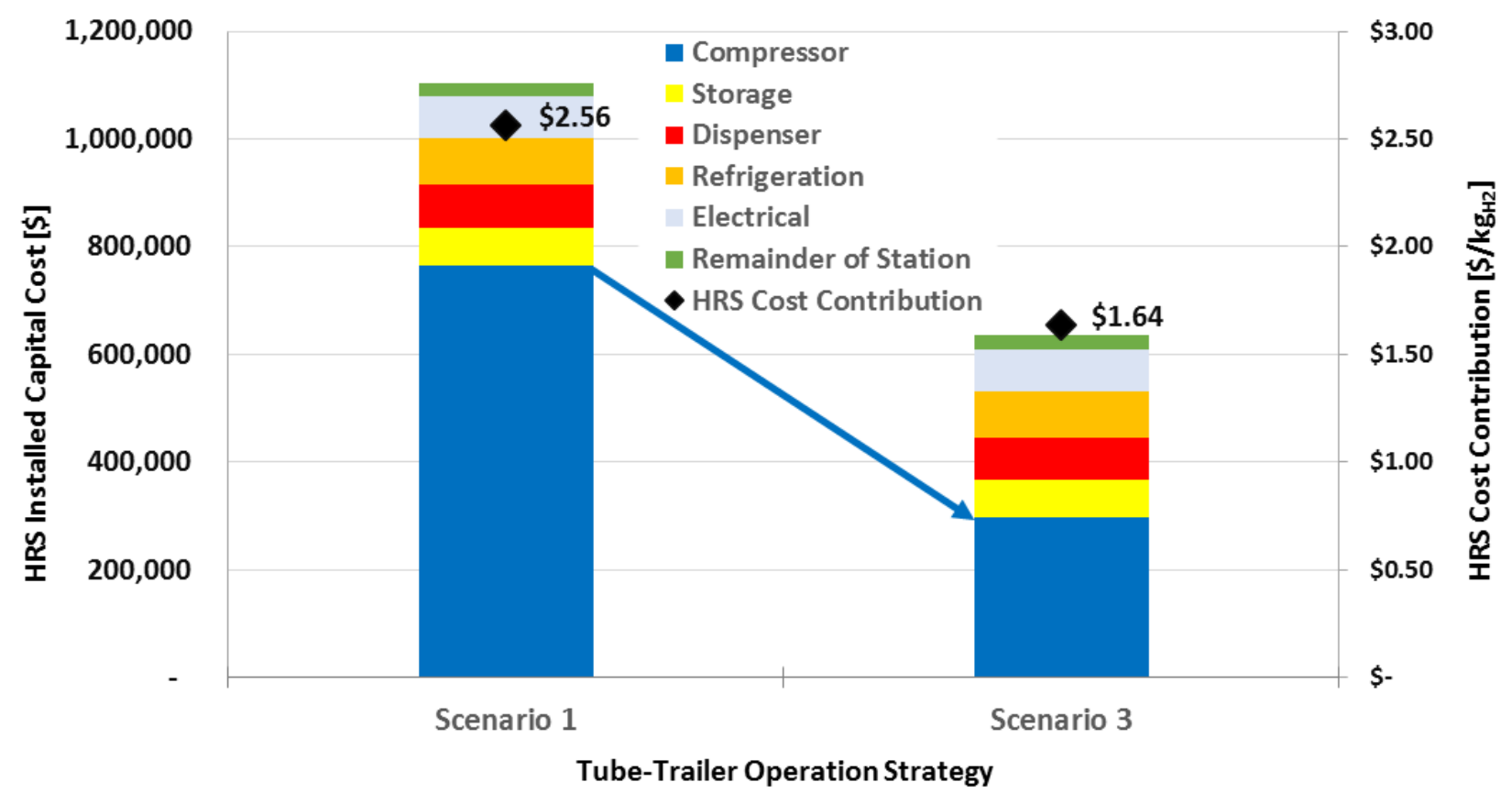

Figure 11: Impact of Tube-Trailer Operation Strategy on HRS Capital Cost and Cost of Hydrogen 
The tube-trailer consolidation strategy improves the economics of the station through its more efficient utilization of the station compressor, with more steady operation during both peak and offpeak hours (instead of just during peak hours). The consequence is more reliable compressor operation, since most of the compressor's reliability issues are associated with unsteady on-off operation. The station's cost-reduction benefits associated with the tube-trailer consolidation concept are multiplied even more in early FCEV markets, in which the cost of dispensed hydrogen is likely to be higher because of the underutilization of station equipment for an extended period of time. With high-pressure tubetrailer deliveries, the cost of a major component of the refueling station (i.e., the compressor) is shifted to upstream of the station (i.e., gas terminals), where the compression equipment is better utilized and where it benefits from the economies of scale [Elgowainy et al. 2012]. Delivering hydrogen via highpressure tube-trailers could be a key factor in enabling widespread station deployment because employing such a delivery concept would also distribute the investment risk among the various players in the hydrogen production, delivery, and refueling market.

\section{Conclusions}

The investment and operating cost of a refueling station can be reduced by implementing an effective operating strategy. Using the tube-trailer to initially fill the vehicle's hydrogen tanks enables the station equipment to satisfy marginally higher demands. By implementing a strategy for consolidating hydrogen within the tube-trailer vessels, the same station equipment can triple the station's capacity while satisfying a higher peak demand with fast fill rates $(1.7 \mathrm{~kg} / \mathrm{min})$. For a given compressor capacity, the tube-trailer consolidation strategy can reduce the compression cost at refueling sites by $60 \%$ and reduce the total investment cost for refueling stations by $40 \%$. Tube-trailers with pressures higher than 250 bar (e.g., 350 and 500 bar) offer greater compression and overall station cost-reduction benefits from using the consolidation strategy. In addition, implementing the consolidation strategy improves the reliability of station compressor operation.

\section{Acknowledgment}

This research effort was supported by the Fuel Cell Technologies Office of the U.S. Department of Energy's Office of Energy Efficiency and Renewable Energy under Contract No. DE-AC02-06CH11357. 


\section{References}

1. BOLAT, P. and THIEL, C., 2013. Hydrogen supply chain architecture for bottom-up energy systems models. Part 1: Developing pathways. International Journal of Hydrogen Energy, 39(17), pp. 8881.

2. BROWN, C., PEREA, H., GARCIA, C. and SKINNER, N., 2013. California Assembly Bill AB 8: Alternative fuel and vehicle technologies: funding programs. California.

3. CARB (CALIFORNIA AIR RESOURCES BOARD), 2014. Annual Evaluation of Fuel Cell Electric Vehicle Deployment and Hydrogen Fuel Station Network Development. California Environmental Protection Agency.

4. CHEN, T., 2008. Hydrogen Delivery Infrastructure Options Analysis. Nexant Inc.

5. ELGOWAINY, A., REDDI, K., MINTZ, M. and BROWN, D., 10/05/2011. 2011 DOE Hydrogen Program Review: Hydrogen Delivery Infrastructure Analysis, Available: http://www.hydrogen.energy.gov/pdfs/review11/pd014_mintz_2011_o.pdf, [01/21/2014].

6. ELGOWAINY, A., REDDI, K., MINTZ, M., BROWN, D., and PASTER, M., 17/05/2012. 2012 DOE Hydrogen Program Review: Hydrogen Delivery Infrastructure Analysis. Available: http://www.hydrogen.energy.gov/pdfs/review12/pd014_mintz_2012_o.pdf [01/21, 2014].

7. ELGOWAINY, A., REDDI, K., MINTZ, M. and BROWN, D., 15/05/2013. 2013 DOE Hydrogen Program Review: Hydrogen Delivery Infrastructure Analysis. Available: http://www.hydrogen.energy.gov/pdfs/review13/pd014_mintz_2013_o.pdf [01/21, 2014].

8. HEXAGON LINCOLN, 2014. TITAN ${ }^{\mathrm{TM}}$ Specifications, Available: http://www.hexagonlincoln.com/product-lines/titan/titan-specifications, [06/13/2014].

9. LIPMAN, T., WITT, M., and ELKE, M., 2013. Lessons learned from the installation and operation of Northern California's first 70-MPa hydrogen fueling station, International Journal of Hydrogen Energy, 38(36), pp. 15868.

10. MINTZ, M., ELGOWAINY, A., and GARDINER, M., 2009. Rethinking Hydrogen Fueling: Insights from Delivery Modeling, Journal of the Transportation Research Board (2139), pp.46.

11. PARKS, G., BOYD, R., CORNISH, J., and REMICK, R., 2014. Hydrogen Station Compression, Storage, and Dispensing Technical Status and Costs, Report NREL/BK-6A10-58564, National Renewable Energy Laboratory, available at http://www.hydrogen.energy.gov/pdfs/58564.pdf, [06/13/2014].

12. REDDI, K., ELGOWAINY, A., and SUTHERLAND, E., 2014. Hydrogen refueling station compression and storage optimization with tube-trailer deliveries, International Journal of Hydrogen Energy (2014), doi: 10.1016/j.ijhydene.2014.09.099.

13. SAE (SOCIETY OF AUTOMOTIVE ENGINEERS), 2010. SAE International Surface Vehicle Technical Information Report: Fueling Protocols for Light Duty Gaseous Hydrogen Surface Vehicles, SAE J2601, SAE International.

14. U.S. DEPARTMENT OF TRANSPORTATION, 1994. Federal Size Regulations for Commercial Motor Vehicles," Federal Highway Administration, Code of Federal Regulations (CFR) Title 23, Part 658.

15. YANG, C., and OGDEN, J., 2007. Determining the lowest-cost hydrogen delivery mode," International Journal of Hydrogen Energy, 32(2), pp.268. 


\section{License:}

"The submitted manuscript has been created by UChicago Argonne, LLC as Operator of Argonne National Laboratory ("Argonne") under Contract No. DE-AC02-06CH11357 with the U.S. Department of Energy. The U.S. Government retains for itself, and others acting on its behalf, a paid-up, nonexclusive, irrevocable worldwide license in said article to reproduce, prepare derivative works, distribute copies to the public, and perform publicly and display publicly, by or on behalf of the Government." 